\title{
Influence of Crystallization and Ageing Time on the Reproducibility of Mesoporous Molecular Sieve SBA-15
}

\author{
Lidiane Sabino da Silva ${ }^{1}$, Artur Lemes Moretti ${ }^{1}$, \\ Gabriela Gonzaga Cher ${ }^{1}$, Pedro Augusto Arroyo ${ }^{1}$
}

\footnotetext{
${ }^{1}$ Chemical Engineering Program, State University of Maringá (UEM), CEP: 87020-900, Maringá, Paraná, Brazil. e-mail: lidiane_eq@hotmail.com, turlemes@gmail.com,gabicher@live.com, arroyo@teracom.com.br
}

\begin{abstract}
The study aimed to assess how the crystallization and ageing times in SBA-15 synthesis influence the reproducibility and particle size of mesoporous molecular sieves. X-ray diffraction showed that higher crystallization times provide greater reproducibility of mesoporous silica, due to the fact that there is no significant variation in the width and intensity of peaks, while the same is not true for shorter crystallization times. Ageing time does not seem to exercise a significant influence when higher crystallization times are used in the synthesis. Scanning electron microscopy observations revealed that shorter crystallization times led to larger crystals in addition to the formation of large agglomerates, whereas with higher crystallization times the trend is to obtain smaller and more uniform grains. It is proposed that hydrogen bonds may be responsible for the formation of smaller particles and it is also established that depending on the synthesis conditions the reproducibility of the process can become low.
\end{abstract}

Keywords: reproducibility, SBA-15, crystallization time, ageing time.

\section{INTRODUCTION}

The mesoporous molecular sieve SBA-15 was synthesized for the first time using an organic surfactant of type Pluronic 123, a triblock copolymer of ethylene oxide (EO) and propylene oxide (PO) with the general formula $\mathrm{EO}_{20} \mathrm{PO}_{70} \mathrm{EO}_{20}$ [1]. Dilute concentrations of Pluronic 123 in an acid medium $(\mathrm{pH}<1)$ produced a hexagonal structure with a pore arrangement similar to MCM-41, which was designated SBA-15 (Saint Barbara no. 15). Using block copolymers instead of low-molecular-weight surfactants, as generally occurs in MCM-41, has the advantage of giving more stable materials, as the silica walls are thicker and the pore diameters larger [2].

The mesoporous molecular sieve SBA-15 was synthesized for the first time using an organic surfactant of type Pluronic 123, a triblock copolymer of ethylene oxide (EO) and propylene oxide (PO) with the general formula $\mathrm{EO}_{20} \mathrm{PO}_{70} \mathrm{EO}_{20}$ [1]. Dilute concentrations of Pluronic 123 in an acid medium ( $\left.\mathrm{pH}<1\right)$ produced a hexagonal structure with a pore arrangement similar to MCM-41, which was designated SBA-15 (Saint Barbara $n^{\circ}$. 15). Using block copolymers instead of low-molecular-weight surfactants, as generally occurs in MCM-41, has the advantage of giving more stable materials, as the silica walls are thicker and the pore diameters larger [2].

In more detail, SBA-15 has a pore size of up to $30 \mathrm{~nm}$ and a wall thickness between 3 and $6.5 \mathrm{~nm}$. Certainly, these features increase the potential of the use of SBA-15 in catalysis or other processes [1]. At the same time, due to their high specific area and ordered array of pores, these materials are suitable for introducing active species such as metals [3].

In the literature, there are several works that deal with various aspects of SBA-15 synthesis such as the temperature, crystallization time, $\mathrm{pH}$, ageing time, template composition, and addition of substances during the synthesis, which affect the structural and adsorption properties of these mesoporous structures [4-8]. In spite of significant advances in this area, there is still great interest in the synthesis of SBA-15 in order to make it simple and feasible to scale up [9]. For these reasons, it is extremely important that the synthesis is easily reproducible.

In addition, the morphology and texture properties of mesoporous silica are extremely important for industrial applications [3, 6, 7, 10,11]. Varying the experimental conditions used in the synthesis of SBA-15 is an easy and efficient method of controlling the textural properties of the mesoporous molecular sieve, 
which may be beneficial for a certain type of application, for example, by providing greater accessibility of reactants to the pores. Thus, there may be an increase in the activity and selectivity of the catalyst [12].

A small particle size and narrow size distribution are essential features of this type of material. It is evident that reducing the particle size from micrometres to nanometres causes substantial changes in the material properties. The smaller the grain size, the higher the specific external area per unit volume and the lower the mass transfer resistance to transport of chemical species [13-15].

From the template synthesis mechanism proposed by researchers of the Mobil Oil Corporation, known as Liquid Crystal Templating [16] several works were developed with the aim of obtaining new mesoporous materials as well as new synthesis routes [2,17-19]. Interaction between the surfactante and the inorganic phase has become one of the most important parameters in the definition of the preparation route of mesoporous materials. Due to the fact that the formation of the materials is still not fully known, it is interesting to perform studies on their syntheses and formation mechanisms, because there is no universal mechanism describing all the crystallization processes of different mesoporous molecular sieves.

Following this reasoning, the present work evaluated how the crystallization and ageing time influence the reproducibility and particle size of the synthesized SBA-15. Furthermore, an additional step to a mechanism described in the literature for the formation of the mesoporous molecular sieve is proposed.

\section{MATERIAL AND METHODS}

\subsection{Synthesis of Mesoporous Molecular Sieve}

The synthesis was performed according to the method proposed in the literature $[1,19]$. The method was chosen primarily because of the use of the copolymer P123 as a structure-directing agent which forms more stable materials [2]. The reagents used were Pluronic $\mathrm{P} 123\left(\mathrm{EO}_{20} \mathrm{PO}_{70} \mathrm{EO}_{20}\right), \mathrm{HCl}$ solution (2mol/L), tetraethyl orthosilicate (TEOS $\mathrm{C}_{8} \mathrm{H}_{12} \mathrm{O}_{4} \mathrm{Si}, 98 \%$ ), and deionized water. First, $4 \mathrm{~g}$ of Pluronic P123, $120 \mathrm{~g}$ of hydrochloric acid solution, and $30 \mathrm{~g}$ of deionized water were mixed in a Teflon container until complete dissolution of the polymer. Then $8.5 \mathrm{~g}$ of TEOS was added to the solution, which was stirred at $40^{\circ} \mathrm{C}$ for crystallization of the material. After this period, the suspension was placed in a stainless steel autoclave lined with Teflon and maintained at $100^{\circ} \mathrm{C}$ during the ageing step. Subsequently, the solid obtained was filtered, washed with excess deionized water, and dried at $100^{\circ} \mathrm{C}$ overnight. The samples were calcined in air under static conditions at $550^{\circ} \mathrm{C}$ for $6 \mathrm{~h}$ at a heating rate of $1{ }^{\circ} \mathrm{C}$ per minute. The crystallization time applied was 3 or $24 \mathrm{~h}$ and the ageing time was 24 or $48 \mathrm{~h}$. The synthesis characteristics of each sample are shown in Table 1:

Table 1: Synthesis characteristics of each sample.

\begin{tabular}{c|c|c}
\hline Sample & Crystallization time (h) & Ageing time (h) \\
\hline 1 & 3 & 24 \\
\hline 2 & 3 & 24 \\
\hline 3 & 3 & 24 \\
\hline 4 & 3 & 24 \\
\hline 5 & 24 & 24 \\
\hline 6 & 24 & 24 \\
\hline 7 & 24 & 24 \\
\hline 8 & 24 & 48 \\
\hline 9 & 24 & 48 \\
\hline 10 & 24 & 24 \\
\hline
\end{tabular}

\subsection{Characterization of Mesoporous Molecular Sieve}

\subsubsection{X-ray diffraction}

Low-angle X-ray diffraction (XRD) patterns were obtained using a Bruker Advance D8 powder diffractometer with $\mathrm{Cu} \mathrm{K} \alpha$ radiation from 0.5 to $5^{\circ}$ with a step size of $0.01^{\circ}$. The interplanar distance was calculated using Bragg's Law, described below: 
$\mathrm{n} \lambda=2 \cdot \mathrm{d} \cdot \operatorname{sen}(\theta)$

$\lambda$ is the wavelength of $\mathrm{Cu} \mathrm{K} \alpha$ radiation $(1.54 \AA)$, $\mathrm{d}$ the interplanar distance, and $\theta$ the Bragg angle.

The unit cell parameter $\left(a_{0}\right)$ of the hexagonal mesoporous arrangement of SBA-15 was obtained from the interplanar distance values and was calculated using the equation for solids with hexagonal symmetry in accordance with the literature [20]:

$$
1 / \mathrm{d}^{2}{ }_{\mathrm{hkl}}=4 \cdot\left(\mathrm{h}^{2}+\mathrm{hk}+\mathrm{l}^{2}\right) / 3 \cdot\left(\mathrm{a}_{0}\right)^{2}+\mathrm{l}^{2} / \mathrm{c}^{2}
$$

Where $\mathrm{c}$ is a constant and $\mathrm{h}, \mathrm{k}$, and $\mathrm{l}$ are the Miller indices of the crystal plane.

\subsubsection{High-Resolution Transmission Electron Microscopy}

High-resolution transmission electron microscopy (HRTEM) was carried out using a JEM 3010 URP microscope at the Electron Microscopy Laboratory of the Brazilian Nanotechnology National Laboratory (LNNano) operated at $300 \mathrm{KV}$ with a LaB6 thermionic electron gun and point-to-point resolution of $0.17 \mathrm{~nm}$. HRTEM images were acquired using a charge-coupled device Gatan 194SC multiscan digital camera, with 1024 X1024 pixels attached to DigitalMicrograph software (Gatan Inc.). Prior to measurement, the solids were ultrasonically dispersed in isopropyl alcohol and the suspension was collected on copper grids covered with a holey carbon thin film, dried, and rapidly transferred to the microscope.

\subsubsection{Adsorption and Desorption with Nitrogen}

Analyses of nitrogen adsorption/desorption were carried out at $-196^{\circ} \mathrm{C}$ on a Micromeritics ASAP 2020 apparatus using approximately $0.100 \mathrm{~g}$ of sample for each measurement. Before the measurements, the samples were degassed under vacuum condition at $300^{\circ} \mathrm{C}$ for $3 \mathrm{~h}$. The specific surface areas were evaluated using the Brunauer-Emmett-Teller (BET) method in the $\mathrm{P} / \mathrm{P}_{0}$ range of $0.05-0.3$ [21]. Pore size distribution curves were calculated from the desorption branch of the nitrogen isotherms using the Barrett-Joyner-Halenda (BJH) method [22], calibrated for cylindrical pores [23]. The total pore volumes were estimated according to nitrogen uptake at a relative pressure $\left(\mathrm{P} / \mathrm{P}_{0}\right)$ of 0.99 . The micropore volume and micropore surface area were estimated by a t-plot method [24].

\subsubsection{Scanning Electron Microscopy}

The morphology and size of the zeolite crystallites were assessed by scanning electron microscopy (SEM) in a Shimadzu SuperScan SS-550 microscope. Prior to obtaining the images, the samples were covered with a gold film by a sputtering process in order to provide electrical conductivity to the material.

\section{RESULTS AND DISCUSSION}

Figure 1 shows the XRD patterns of the SBA-15 synthesized with a crystallization time of $3 \mathrm{~h}$ and ageing time of $24 \mathrm{~h}$ (samples 1 to 4 ), crystallization time of $24 \mathrm{~h}$ and ageing time of $24 \mathrm{~h}$ (samples 5 to 8 ), and crystallization time of $24 \mathrm{~h}$ and ageing time of $48 \mathrm{~h}$ (samples 9 and 10). Replicas were performed in order to verify the reproducibility of the synthesized samples. 

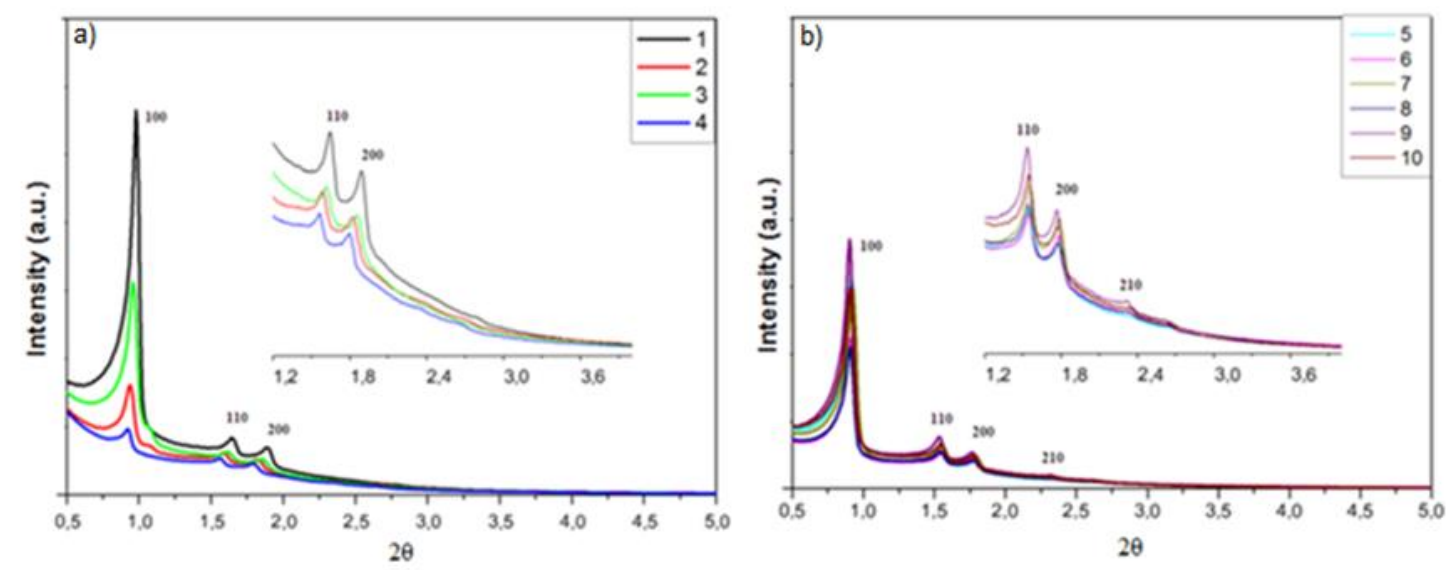

Figure 1: XRD patterns of synthesized SBA-15. a) $3 \mathrm{~h}$ crystallization interval and b) $24 \mathrm{~h}$ crystallization interval.

The synthesis of molecular sieve SBA-15 was confirmed through the X-ray diffractograms shown in Figure 1, which are similar to those obtained in the literature. 1 Samples prepared in a 3 h crystallization interval showed three well-defined peaks indexed to the planes (100), (110), and (200), which are indicative of the hexagonal symmetry of SBA-15. On increasing the crystallization time to $24 \mathrm{~h}$, in addition to the previously mentioned planes, the plane (210) appears in the diffractogram, which is indicative of the hexagonal symmetry of SBA-15 with a high degree of organization.1 It is observed that the prolongation of the crystallization time leads to a better organized product and more highly polymerized silica network [2].

In the diffractograms shown in Figure 1(b), increasing the ageing time does not appear to have a significant effect on the ordered arrangement of the samples. This may occur due to the high crystallization time, which can cause the effect of ageing time on the crystallinity to be negligible [4].

As reported by Fulvio and Jaroniec [9] the structure formation of SBA-15 really occurs during the first few hours of crystallization. However, the reproducibility of the results has not been verified for reduced ranges of this step. As shown in Figure 1(a), with short periods of crystallization, the peak intensities in the XRD patterns varied significantly from one synthesis to another, which did not occur in the syntheses in which longer crystallization times were used.

Interplanar distances and unit cell parameters $\left(\mathrm{a}_{0}\right)$ of the synthesized SBA-15 are presented in Table 2. The values obtained were compared with those presented by ZHAO et al. [1].

Table 2: Interplanar distances and unit cell parameters of SBA-15.

\begin{tabular}{l|l|l|l|l}
\hline \multicolumn{1}{c|}{ SAMPLE } & $\mathbf{D}_{100}(\mathbf{N M})$ & $\mathbf{D}_{110}(\mathbf{N M})$ & $\mathbf{D}_{200}(\mathbf{N M})$ & $\mathbf{A}_{\mathbf{0}}(\mathbf{N M})^{*}$ \\
\hline 1 & 9.0 & 5.4 & 4.7 & 10.4 \\
\hline 2 & 9.4 & 5.6 & 4.8 & 10.9 \\
\hline 4 & 9.2 & 5.5 & 4.8 & 10.7 \\
\hline 5 & 9.6 & 5.7 & 4.9 & 11.1 \\
\hline 6 & 9.6 & 5.7 & 4.9 & 11.1 \\
\hline 7 & 9.7 & 5.7 & 5.0 & 11.2 \\
\hline 9 & 9.6 & 5.7 & 4.9 & 11.1 \\
\hline 10 & 9.7 & 5.7 & 5.0 & 11.2 \\
\hline ZHAO et al. $[1]$ & 9.8 & 5.8 & 5.0 & 11.3 \\
\hline Cell param & 9.7 & 5.7 & 5.0 & 11.2 \\
\hline
\end{tabular}

*Cell parameters relating to the plane (100).

The values were closer to the standard in the samples which were treated with the longer crystallization time, indicating the importance of this step in the synthesis of the material.

Figure 2 shows the HRTEM images. A well-ordered hexagonal array of mesopores is observed for the 
samples when the electron beam is parallel to the main axis of the cylindrical pores. When the electron beam is perpendicular to the main axis, the cylindrical pores are viewed from the side as a striped image. The images confirm the well-ordered hexagonal arrays of mesopores with one-dimensional channels, indicating a 2$\mathrm{D}$ hexagonal (P6mm) mesostructure. The distance between the centres of two adjacent pores is about $100 \AA$ and the pore diameter is about $60 \AA$, in accordance with the characteristic parameters of the SBA-15 structure [1].

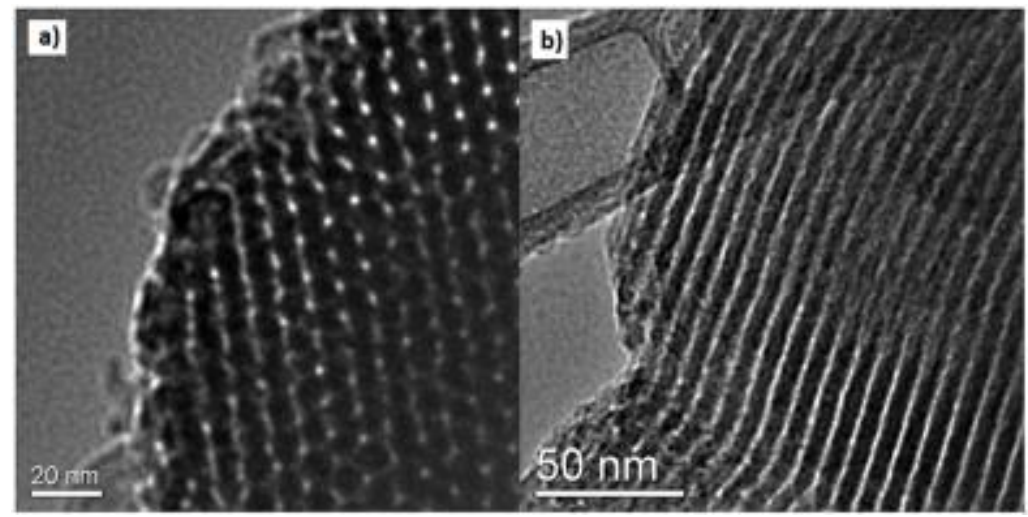

Figure 2: Transmission electron microscopy images of the SBA-15 (sample 8). Electron beam parallel (a) and perpendicular (b) to the main axis of the pores.

Nitrogen adsorption isotherms for samples are shown in Figure 3. Four distinct regions are observed: (a) initially, adsorption occurs in regions of low relative pressure $\left(\mathrm{P} / \mathrm{P}_{0}<0.02\right)$, corresponding to the filling of micropores; (b) then, there is a linear increase in adsorbed volume due to adsorption on single- and multilayers on the material surface, including the mesoporous surface; (c) the increase in adsorbed volume at intermediate pressures is attributed to the phenomenon of capillary condensation in primary mesopores; (d) finally, the increased volume adsorbed at high relative pressures is associated with adsorption in the multilayer and/or condensation of fluid in the secondary mesopores. In this case, the uniform cylindrical pores are considered as the primary mesopores while other mesopores are considered as secondary mesopores [23].

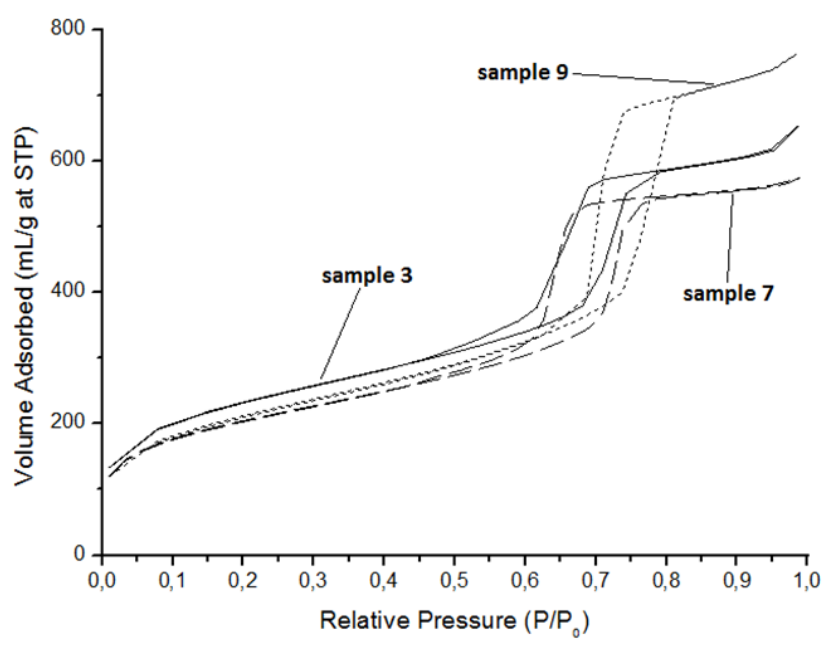

Figure 3: Adsorption and desorption isotherms of nitrogen of SBA-15.

In all cases, the isotherms are of type IV and exhibit hysteresis loops of type H1 according to the IUPAC classification, typical of materials with pores of constant cross-section (for instance, cylindrical or hexagonal) [25]. The shape of the nitrogen adsorption-desorption isotherm is characteristic for a well-formed SBA-15 material.

In the sample that was synthesized with the shortest crystallization time (sample 3), an additional capillary condensation is observed at partial pressures greater than 0.90 due to the filling of textural mesopores [26]. Textural mesoporosity is the porosity arising from non-crystalline intraaggregate voids and spaces 
formed by interparticle contacts [27]. It has been reported [28] that these materials have four different levels of structure: particles, grains, crystallites, and mesopores [29], which could lead to this additional porosity. This can be better explained and understood through electronic scanning microscopy, as will be shown later.

Table 3 presents the textural properties of the synthesized materials. The specific area is shown by the BET method, the area of micropores by the t-plot method, and the total volume and average diameter of pores by the BJH method. The results are within the ranges obtained in the literature $[1,19]$.

Table 3: Textural properties of SBA-15.

\begin{tabular}{c|c|c|c|c}
\hline SAMPLE & $\mathbf{S}_{\text {BET }}\left(\mathbf{M}^{2} / \mathbf{G}\right)$ & $\mathbf{S}_{\text {T-PLOT }}\left(\mathbf{M}^{2} / \mathbf{G}\right)$ & $\mathbf{V}_{\text {TOTAL }}\left(\mathbf{C M}^{3} / \mathbf{G}\right)$ & $\mathbf{D}(\mathbf{N M})$ \\
\hline 3 & 805 & 166 & 0.892 & 5.58 \\
\hline 7 & 710 & 133 & 0.813 & 5.34 \\
\hline 9 & 743 & 114 & 1.12 & 6.85 \\
\hline
\end{tabular}

Figure 4 shows the micrographs obtained by SEM. The analysis was performed in order to verify the morphology of the synthesized samples. It is observed that in samples synthesized with a crystallization time of $3 \mathrm{~h}$, there was a variation in particle size of nanometres to micrometres, whereas the samples that were synthesized for a longer crystallization time showed a lower average diameter without many variations. In the images 1(a) and (b), the grains are so agglomerated that they seem like a single particle, such is the interaction that unites them.

Particle sizes presented in Figure 4 correspond to the variation of intensity and peak widths in the XRD patterns shown in Figure 1. The decrease in intensity and increase in the width of the peaks are expected when there is a reduction in the size of the crystal [30].
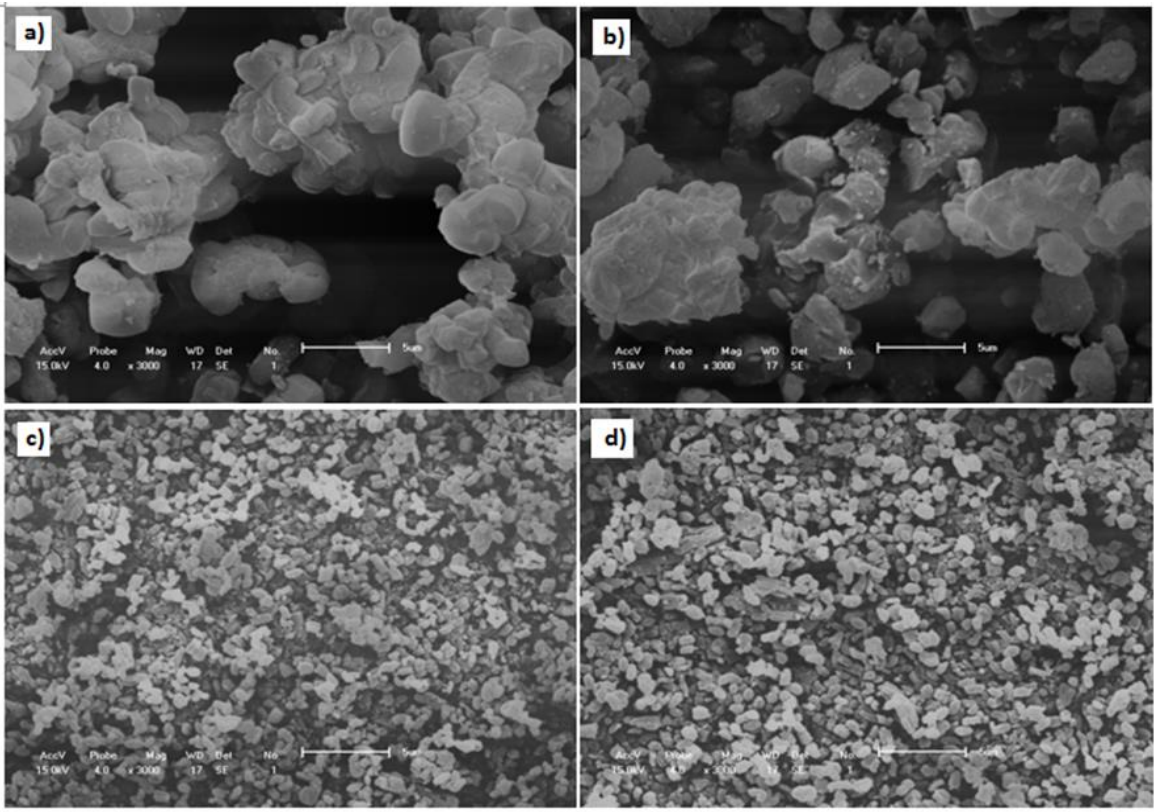

Figure 4: Micrographs obtained by scanning electronic microscopy of SBA-15 samples. (a) and (b) are samples synthesized with a crystallization time of $3 \mathrm{~h}$, while (c) and (d) are samples synthesized with a crystallization time of $24 \mathrm{~h}$. Scale: $500 \mu \mathrm{m}$.

A curious fact observsed in the syntheses performed is the large size of some particles in samples whose crystallization time was shorter. As has already been reported in the literature [2], the molecular causes of this attraction between the particles are unclear. FLODSTROM et al. [2] proposed that the mechanism of SBA-15 formation using P123 as a structure-directing agent follows five steps: (1) hydrolysis of silica precursor; (2) silica polymerization; (3) growth of flocs; (4) association of flocs to form larger flocs; and (5) micelle coalescence forming cylindrical aggregates. It is well established that poly(ethylene oxide) adsorbs on silica surfaces [31]. Similarly, micelles based on EO non-ionic surfactants also adsorb on such surfaces, as do Pluronic micelles [32]. The attractions that occur can be attributed to hydrogen bonds between the hydrolyzed silica and $\mathrm{OE}$ groups ( $\mathrm{SiOH}-\mathrm{OE}$ ) as well as direct interactions between the EO group and silicon (EO$\mathrm{Si}$ ) [33]. Thus, as the polymerization of silica progresses, its affinity for the EO layer should increase and, as long there is an excess of EO palisade layers, there is the opportunity for a bridging interaction that will con- 
nect two micellar aggregates, corresponding to the fifth step of the process proposed by FLODSTROM et al. [2]. If the interaction is strong enough, it will cause the formation of aggregates corresponding to larger grains. However, if the attraction is not strong enough, hydrogen atoms could breaking the connections between the groups that form aggregates through hydrogen bonds, thus forming smaller grains. Due to the fact that the hydrogen bonds are extremely strong compared to other connections, over time, the system would become more stable. This would explain why the synthesis that occurred over a longer crystallization time led to a smaller grain size. It would also be in accordance with FLODSTROM et al. [2], who affirm that if the silica polymerization is allowed to proceed too far, passing the gel point, the micelle-micelle coalescence can be expected to become increasingly hindered and ultimately impossible, whereas the structural changes of the aggregates occur simultaneously with the progression of the silica polymerization. Thus, there is a tendency to obtain particles of reduced size when the synthesis is performed using long periods of crystallization.

\section{CONCLUSIONS}

According to the results obtained, it can be inferred that the crystallization time exerts a significant influence on the reproducibility and particle size of synthesized samples. A long crystallization time ( $24 \mathrm{~h})$ gives homogeneous particles that are smaller in size as well as more reproducible, which is not the case for the SBA15 synthesized in $3 \mathrm{~h}$. The ageing time does not seem to exert significant influence on synthesis when extended crystallization times are used. The formation of smaller particles can be explained by the breaking of connections that form the agglomerates, resulting in smaller particles and subsequent formation of hydrogen bonds, which make the system more stable. Thus, a decrease in the synthesis time may affect the effective reproducibility and particle size of the samples.

\section{ACKNOWLEDGEMENTS}

The authors are grateful to CAPES/Brazil and CNPq/Brazil for financial support and to COMCAP/UEM and LNNano/CNPEM for SEM and TEM analyses.

\section{BIBLIOGRAPHY}

[1] ZHAO, D., FENG, J., HUO, Q., et al., "Triblock copolymer syntheses of mesoporous silica with periodic 50 to 300 angstrom pores", Science, v. 279, pp. 548-552, 1998.

[2] FLODSTROM, K., WENNERSTROM, H., ALFREDSSON, V., "Mechanism of mesoporous silica formation. A time-resolved NMR and TEM study of silica-block copolymer aggregation", Langmuir v. 20, pp. 680-688, 2004.

[3] NAIK, B., GHOSH, N.N., "A review on chemical methodologies for preparation of mesoporous silica and alumina based materials", Nanotechnology, v. 3, pp. 213-224, 2009.

[4] JAFARI, M., NOURI, A., KAZEMIMOGHADAN, M., et al., "Investigations on hydrothermal synthesis parameters in preparation of nanoparticles of LTA zeolite with the aid of TMAOH", Powder Technology, v. 237, pp. 442-449, 2013.

[5] WU, S., HAN, Y., ZOU, Y-C., et al., "Synthesis of heteroatom substituted SBA-15 by the pH-adjusting method", Chemistry of Materials, v. 16, pp.486-492, 2004.

[6] KIM, J.M., SAKAMOTO, Y., HWANG, Y.K., et al., "Structural design of mesoporous silica materials by micelle-packing control using blends of amphiphilic block copolymers", The Journal of Physical Chemistry $B$, v. 106, pp. 2552-2558, 2002.

[7] ZHAO, D., SUN, J., LI, Q., et al., "Morphological control of highly ordered mesoporous silica SBA-15", Chemistry of Materials, v. 12, pp.275-279, 2000.

[8] MAJDA, D., NAPRUSZEWSKA, B.D., ZIMOWSKA, M., et al., "Porosity of SBA-15 after functionalization of the surface with aminosilanes", Microporous and Mesoporous Materials, v. 234, pp. 98-106, 2016.

[9] FULVIO, P.F., JARONIEC, M., "Optimization of synthesis time for SBA-15 materials", Studies in Surface Science and Catalysis, v. 156, pp.75-82, 2005.

[10] PATHAN, S., SOLANKI, P., PATEL, A., "Functionalized SBA-15 for controlled release of poorlysoluble drug, Erythromycin", Microporous and Mesopurous Materials, v. 258, pp. 114-121, 2018.

[11] PENG, K., LI, X., LIU, X., et al., "Hydrothermally stable Nb-SBA-15 catalysts applied in carbohydrate conversion to 5-hydroxymethyl furfural", Molecular Catalysis, v. 441, pp. 72-80, 2017. 
[12] KLIMOVA, T., ESQUIVEL, A., REYES, J., et al., "Factorial design for the evaluation of the influence of synthesis parameters upon the textural and structural properties of SBA-15 ordered materials", $M i$ croporous and Mesoporous Materials, v. 93, pp.331-343, 2006.

[13] CHARKHI, A., KAZEMEINI, M., AHMADI, S.J., et al., "Fabrication of granulated NaY zeolite nanoparticles using a new method and study the adsorption properties", Powder Technology, v. 231, pp.1-6, 2012.

[14] CHARKHI, A., KAZEMIAN, H., KAZEMEINI, M., "Optimized experimental design for natural clinoptilolite zeolite ball milling to produce nano powders", Powder Technology, v. 203, pp. 389-396, 2010.

[15] BRAR, T., FRANCE, P., SMIRNIOTIS, P.G., "Control of crystal size and distribution of zeolite A", Indutrial and Engineering Chemistry Research, v. 40, pp.1133-1139, 2001.

[16] BECK, J.S., VARTULI, C., ROTH, W.J., et al., "A new family of mesoporous molecular sieves prepared with liquid crystal template", Journal of the American Chemical Society, v. 114, pp.10834-10843, 1992.

[17] WAN, Y., ZHAO, D., "On the controllable soft-templating approach to mesoporous silicates", Chemical Reviews, v. 107, pp. 2821-2860, 2007.

[18] HOFFMANN, F., CORNELIUS, M., MORELL, J., et al., "Silica-based mesoporous organic-inorganic hybrid materials”, Angewandte Chemie International Edition, v. 45, pp.3216-3251, 2006.

[19] ZHAO, D., HUO, Q., FENG, J., et al., "Nonionic triblock and star diblock copolymer and oligomeric surfactant syntheses of highly ordered, hydrothermally stable, mesoporous silica structures", Journal of the American Chemical Society, v. 120, pp. 6024-6036, 1998.

[20] CULLITY, B.D., STOCK, S.R., Elements of X-Ray Diffraction, 3 ed., New Jersey, Prentice Hall, 2001.

[21] BRUNAUER, S., EMMETT, P.H., TELLER, E., “Adsorption of gases in multimolecular layers”, Journal of the American Chemical Society, v. 60, pp.309-319, 1938.

[22] BARRETT, E.P., JOYNER, L.G., HALENDA, P.P., "The determination of pore volume and area distributions in porous substances. I. Computations from nitrogen isotherms", Journal of the American Chemical Society, v. 73, pp.373-380, 1951.

[23] KRUK, M., JARONIEC, M., “Application of large pore MCM-41 molecular sieves to improve pore size analysis using nitrogen adsorption measurements", Langmuir, v. 13, pp.6267-6273, 1997.

[24] LIPPENS, B.C., LINSEN, B.G., BOER, J.H., "Studies on pore systems in catalysts. I. The adsorption of nitrogen; apparatus and calculation", Journal of Catalysis, v. 3, pp.32-37, 1964.

[25] SCHMAL, M., Catálise Heterogênea, 1ed., Rio de Janeiro, Editora Synergia, 2012.

[26] PAULY, R.T., LIU, Y., PINNAVAIA, T.J., et al., "Textural mesoporosity and the catalytic activity of mesoporous molecular sieves with wormhole framework structures", Journal of the American Chemical Society, v. 121, pp. 8835-8842, 1999.

[27] TANEV, P.T., PINNAVAIA, T.J., "Mesoporous silica molecular sieve prepared by ionic and neutral surfactant templating: a comparison of physical properties" Chemistry of Materials, v. 8, pp.2068-2079, 1996.

[28] SONWANE, C.G., BHATIA, S.K., "Structural characterization of MCM-41 over a wide range of length scales", Langmuir, v. 15, pp. 2809-2816, 1999.

[29] SONWANE, C.G., BHATIA, S.K., CALOR, N.J., "Characterization of surface roughness of MCM-41 using methods of fractal analysis", Langmuir, v. 15, pp.4603-4612, 1999.

[30] SONG, W., JUSTICE, R.E., JONES, C.A., et al., "Size-dependent properties of nanocrystalline silicalite synthesized with systematically varied crystal sizes", Langmuir, v. 20, pp. 4696-4702, 2004.

[31] DIJT, J.C., STUART, M.A.C., HOFMAN, J.E., FLEER, G.J., "Kinetics of polymer adsorption in stagnation point flow", Colloids and Surfaces, v. 51, pp. 141-158, 1990.

[32] MALMSTEN, M., LINSE, P., COSGROVE, T., "Adsorption of PEO-PPO-PEO block copolymer at sílica”, Macromolecules, v. 25, pp. 2474-2481, 1992.

[33] TAKAHASHI, R., NAKANISHI, K., SOGA, N., "Aggregation behavior of alkoxide-derived silica in sol-gel process in presence of poly(ethylene oxide)", Journal of Sol-Gel Science and Technology, v. 17, pp.7-18, 2000. 


\section{ORCID}

Lidiane Sabino da Silva

Artur Lemes Moreti

Gabriela Gonzaga Cher

Pedro Augusto Arroyo
https://orcid.org/0000-0001-7569-907X

https://orcid.org/0000-0001-6799-1548

https://orcid.org/0000-0002-4273-4841

https://orcid.org/0000-0001-7350-0469 